\title{
Measuring the Food Environment: A Systematic Technique for Characterizing Food Stores Using Display Counts
}

\author{
Cassandra Miller, ${ }^{1}$ J. Nicholas Bodor, ${ }^{2}$ and Donald Rose ${ }^{2}$ \\ ${ }^{1}$ Healthy Communities Institute, 2054 University Avenue, 3rd Floor, Berkeley, CA 94704, USA \\ ${ }^{2}$ School of Public Health and Tropical Medicine, Tulane University, 1440 Canal Street, Suite 2301, New Orleans, LA 70112, USA
}

Correspondence should be addressed to Donald Rose, diego@tulane.edu

Received 10 February 2012; Accepted 26 March 2012

Academic Editor: Stef P. J. Kremers

Copyright (C) 2012 Cassandra Miller et al. This is an open access article distributed under the Creative Commons Attribution License, which permits unrestricted use, distribution, and reproduction in any medium, provided the original work is properly cited.

\begin{abstract}
Marketing research has documented the influence of in-store characteristics-such as the number and placement of display stands - on consumer purchases of a product. However, little information exists on this topic for key foods of interest to those studying the influence of environmental changes on dietary behavior. This study demonstrates a method for characterizing the food environment by measuring the number of separate displays of fruits, vegetables, and energy-dense snack foods (including chips, candies, and sodas) and their proximity to cash registers in different store types. Observations in New Orleans stores $(N=172)$ in 2007 and 2008 revealed significantly more displays of energy-dense snacks than of fruits and vegetables within all store types, especially supermarkets. Moreover, supermarkets had an average of 20 displays of energy-dense snacks within 1 meter of their cash registers, yet none of them had even a single display of fruits or vegetables near their cash registers. Measures of the number of separate display stands of key foods and their proximity to a cash register can be used by researchers to better characterize food stores and by policymakers to address improvements to the food environment.
\end{abstract}

\section{Introduction}

Over the past decade, there has been a large increase in research on the neighborhood food environment, with a number of studies documenting associations between the food environment and dietary intake or weight status [113]. These and other studies have led to recommendations by scientific panels and policy makers that promote improvements in neighborhood access as a strategy for dealing with the obesity epidemic. For example, the Institute of Medicine listed improving neighborhood access to healthy food as one of the key actions that local governments could take to address the child obesity epidemic [14], and the US President's budget for 2012 included funding for a fresh food financing initiative to improve food access in underserved areas [15].

Despite the tremendous growth, the field is still relatively new, and more research is needed on methods to better-characterize the food environment. One approach to studying it has focused on measures of access to retail food outlets, such as distance to the nearest supermarket $[3,16]$ or number of supermarkets within a defined area $[1,4,6,10]$. A second line of research has focused on measures of food within the store. For example, in-store measurements of shelf space have been conducted to study the availability of different types of foods within stores [17], while other studies have looked at inventories of different types of foods or the pricing of foods $[8,18-28]$.

Marketing research has demonstrated that the in-store environment affects consumer purchasing decisions. It is well known, for example, that the amount of shelf space is an important determinant of sales [29]. Other studies have found that additional display stands influence purchasing behavior [29-32]. For example, in their classic study Wilkinson et al. [32] found that sales increased between 77 and $243 \%$ when a brand was displayed in a secondary location. Increasing the number of display stands of a product increases the likelihood that a consumer will encounter it in the store, and thus increases the probability of its purchase, particularly for impulse items. In marketing research that 
investigated both consumer and in-store characteristics, Inman and coauthors [31] found that additional displays increase unplanned purchases by almost $40 \%$ over baseline estimates. The importance of gaining visual attention of the consumer has also been documented in point of purchase studies [33].

Despite the importance of the number of display stands for influencing consumer purchases, and the relative ease in which these data can be collected, very few studies have provided evidence on this variable for foods of particular interest to dietitians and nutritionists $[34,35]$. In this study we demonstrate a method for characterizing the food environment by measuring the number of separate displays of various foods and their proximity to a cash register in different types of stores. Because of their documented importance to public health, we focus on fruits, vegetables, and energy-dense snack foods $[36,37]$.

\section{Methods}

A census of all food stores in the city of New Orleans was developed in the fall of 2007 . We began with a commercial list of stores from InfoUSA, which we verified on the ground to assure that listed stores were still open and that new stores were included in the list. Stores were categorized into one of six types: supermarkets, midsize food stores, small food stores, convenience stores (including those attached to a gas station), drug stores, and general merchandise stores. The category of general merchandise stores included local discount retailers and chain discount "dollar" stores that sell a variety of consumer goods in addition to packaged foods. North American Industry Classification System (NAICS) codes and sales data from InfoUSA were used to categorize the stores. Stores with a "supermarket and other grocery store" NAICS code that had annual sales greater than $\$ 5$ million dollars were classified as supermarkets. Stores with this same code and sales between $\$ 1$ million and \$5 million dollars were classified as midsize food stores, and those with less than $\$ 1$ million annual sales were categorized as small food stores. Other store types did not rely on sales data for classification and were based directly on the NAICS codes. New stores found on the ground were classified into one of the six categories using information on store characteristics (e.g., number of registers, inventory sold). A 30\% random sample of stores was chosen. Additional details regarding development of the store census and sampling have been described previously [38].

In-store observations were taken for 90 stores in 2007 and 113 stores in 2008, with 31 stores observed in both 2007 and 2008. A comparison of data for stores observed in both years did not reveal any significant differences, so these stores were randomly assigned measurements from one of the two years. A total of 172 unique stores were observed, forming the analytic sample for this paper.

Teams of two observers per store collected information on the number of separate displays for five broad categories of fruits and vegetables - fresh fruits, fresh vegetables, canned fruits, canned vegetables and frozen vegetables - and five types of energy-dense snack foods-salty snacks (such as chips and nuts), cookies and crackers, doughnuts and pastries, candies, and carbonated beverages. A continuous linear aisle, or a portion thereof, devoted to a given food category (e.g., fresh fruits), regardless of the number of vertical shelves, was counted as one display, as was a separate island devoted to a given food category. If items for the same food category appeared in two separate linear shelves (e.g., such as in a different aisle, or on opposite facing shelves within the same aisle) they were counted as two separate displays. Displays were counted only once, regardless of the number of specific foods within a given category (e.g., a display aisle of fresh apples, bananas, and/or other fruits was counted as a single display of fresh fruits) nor were they separated by brand (e.g., two or more brands of canned pineapples in a display aisle was counted as a single display). The same method was applied to all food categories, including energy-dense snacks, where brand and type within each snack category were not considered when counting displays. We did not limit our counting of a display to a minimum or maximum length. Observers also recorded whether each separate display was within one meter of a cash register. Interobserver reliability for our method was high with a Pearson correlation value of 0.997 for fruits and vegetables and a value of 0.968 for snacks. Paired $t$-tests showed no significant differences between the mean numbers of displays counted between observers. Supercenters, such as Wal-Mart, were excluded from the analysis, because of the inherent differences in supercenters from other retail food outlets. Additional details on the in-store protocol can be requested from the authors.

Analysis of variance (ANOVA) was used to assess overall differences $(P<0.05)$ in the number of displays by store type. The least significant difference (LSD) test was used post hoc to assess differences in the number of displays for pair-wise combinations of stores. Within a store type (e.g., supermarkets), a paired sample $t$-test was used to assess the difference between the total number of fruit and vegetable displays versus the total number of energy-dense snack food displays. For clarity of presentation, and because of its overriding policy interest, these aggregate food groups (i.e., all fruits and vegetables, all energy-dense snack foods) were used for statistical testing of differences. Data were analyzed using SPSS (version 16.0.1, 2007, SPSS Inc, Chicago, IL, USA). This study is exempt from institutional review as it did not involve human subjects.

\section{Results}

Of the 172 stores that were surveyed, 8 were supermarkets. The most frequently observed stores in the study were convenience stores $(n=69)$ and small stores $(n=63)$.

Almost all stores sold each of the 5 energy-dense snack foods, but the availability of fruits and vegetables differed markedly by store type. Fresh fruits and vegetables were available at all supermarkets and $80 \%$ of small stores, but only at $45 \%$ of convenience stores and $6 \%$ of drug stores (results not shown). Twenty-eight percent of convenience stores did not sell fruits or vegetables of any kind, that is, neither fresh, canned or frozen. 
TABLE 1: Mean number of separate displays, by food group and store type, New Orleans, 2007-2008.

\begin{tabular}{|c|c|c|c|c|c|c|c|c|c|c|c|c|}
\hline \multirow[t]{2}{*}{ Food group } & \multicolumn{2}{|c|}{$\begin{array}{l}\text { Supermarket } \\
\qquad(n=8)\end{array}$} & \multicolumn{2}{|c|}{$\begin{array}{c}\text { Midsized } \\
(n=8)\end{array}$} & \multicolumn{2}{|c|}{$\begin{array}{l}\text { Small store } \\
\quad(n=63)\end{array}$} & \multicolumn{2}{|c|}{$\begin{array}{l}\text { Conven }^{1} \\
(n=69)\end{array}$} & \multicolumn{2}{|c|}{$\begin{array}{l}\text { Drug store } \\
(n=16)\end{array}$} & \multicolumn{2}{|c|}{$\begin{array}{c}\text { Genl merch }{ }^{2} \\
(n=8)\end{array}$} \\
\hline & Mean & SD & Mean & SD & Mean & $\mathrm{SD}$ & Mean & SD & Mean & $\mathrm{SD}$ & Mean & SD \\
\hline All fruits and vegetables ${ }^{3}$ & $20.1^{\mathrm{a}}$ & 9.9 & $9.1^{\mathrm{b}}$ & 6.5 & $5.8^{\mathrm{c}}$ & 3.9 & $2.7^{\mathrm{d}}$ & 2.6 & $3.1^{\mathrm{d}}$ & 2.7 & $5.1^{\mathrm{cd}}$ & 4.4 \\
\hline Fresh fruits and vegetables & 12.8 & 6.8 & 3.8 & 2.7 & 2.4 & 2.1 & 0.9 & 1.3 & 0.1 & 0.5 & 1.1 & 3.2 \\
\hline Fresh fruits & 6.1 & 2.2 & 2.0 & 1.8 & 1.2 & 1.1 & 0.5 & 0.8 & 0.1 & 0.5 & 0.5 & 1.4 \\
\hline Fresh vegetables & 6.6 & 4.9 & 1.8 & 1.0 & 1.2 & 1.2 & 0.4 & 0.8 & 0.0 & 0.0 & 0.6 & 1.8 \\
\hline Can/froz fruits and vegetables & 7.4 & 3.9 & 5.4 & 4.2 & 3.4 & 2.3 & 1.8 & 1.6 & 2.9 & 2.4 & 4.0 & 2.6 \\
\hline Canned fruits & 2.5 & 1.8 & 2.4 & 2.5 & 1.4 & 1.0 & 0.8 & 0.8 & 1.9 & 2.0 & 2.0 & 0.8 \\
\hline Canned vegetables & 3.5 & 2.5 & 2.1 & 1.7 & 1.7 & 1.3 & 0.9 & 0.8 & 1.0 & 0.6 & 2.0 & 2.3 \\
\hline Frozen vegetables & 1.4 & 0.5 & 0.9 & 0.4 & 0.4 & 0.6 & 0.1 & 0.3 & 0.0 & 0.0 & 0.0 & 0.0 \\
\hline All energy-dense snack foods ${ }^{3}$ & $79.8^{\mathrm{a}}$ & 51.3 & $21.8^{\mathrm{bc}}$ & 5.7 & $17.3^{\mathrm{c}}$ & 6.1 & $16.8^{\mathrm{c}}$ & 7.3 & $24.5^{\mathrm{b}}$ & 10.7 & $29.3^{\mathrm{b}}$ & 12.2 \\
\hline Candy & 18.3 & 13.0 & 5.4 & 2.6 & 3.1 & 1.6 & 2.9 & 1.6 & 8.8 & 5.1 & 9.3 & 3.5 \\
\hline Salty snack foods & 22.9 & 14.1 & 6.5 & 3.3 & 4.3 & 2.2 & 4.4 & 2.6 & 5.4 & 2.9 & 7.4 & 4.7 \\
\hline Cookies and crackers & 14.4 & 11.0 & 3.3 & 2.1 & 3.2 & 1.5 & 2.9 & 1.7 & 4.4 & 2.4 & 5.0 & 1.9 \\
\hline Doughnuts and pastries & 12.5 & 8.8 & 2.8 & 1.5 & 2.4 & 1.4 & 2.7 & 1.6 & 1.8 & 1.4 & 3.0 & 1.6 \\
\hline Carbonated beverages & 11.8 & 8.1 & 3.9 & 1.7 & 4.3 & 2.0 & 3.9 & 2.0 & 4.2 & 1.6 & 4.6 & 2.4 \\
\hline
\end{tabular}

1,2 "Conven" refers to convenience stores, and "Genl merch" refers to general merchandise stores.

${ }^{3}$ Analysis of variance (ANOVA) was used to study the difference by store type in the total number of displays of fruits and vegetables. The overall ANOVA was significant $(P<0.05)$. The LSD test was used post hoc to test the difference between pairs of stores. Store types sharing a common superscript (e.g., convenience, drug, and general merchandise stores) were not significantly different from each other on number of displays of this food group. A separate ANOVA was done and found to be significant $(P<0.05)$ for differences in energy-dense snack foods by store type. Within each store type, paired sample $t$-tests showed significantly $(P<0.05)$ more energy-dense snack displays than fruit and vegetable displays.

TABle 2: Mean number of displays within $1 \mathrm{~m}$ of a cash register, by food group and store type, New Orleans, 2007-2008.

\begin{tabular}{lccccc}
\hline \multirow{2}{*}{ Store type } & & \multicolumn{2}{c}{$\begin{array}{c}\text { All fruits and } \\
\text { vegetables }\end{array}$} & \multicolumn{2}{c}{$\begin{array}{c}\text { All } \\
\text { energy-dense } \\
\text { snack foods }\end{array}$} \\
& $N$ & Mean & SD & Mean & SD \\
\hline Supermarkets & 8 & 0.0 & 0.0 & 19.9 & 17.0 \\
Midsized stores & 8 & 1.0 & 2.1 & 5.9 & 3.9 \\
Small stores & 63 & 0.3 & 0.5 & 2.8 & 2.8 \\
Convenience stores & 69 & 0.2 & 0.5 & 2.5 & 1.9 \\
$\begin{array}{l}\text { Drug stores } \\
\text { General }\end{array}$ & 16 & 0.2 & 0.4 & 5.5 & 3.1 \\
merchandise stores & 8 & 0.0 & 0.0 & 4.9 & 2.2 \\
\hline
\end{tabular}

Supermarkets not only had the greatest number of separate displays of fruits and vegetables (mean $=20 \pm 10$ ) but also had a much greater number of separate displays of energy-dense snack foods (mean $=80 \pm 51$ ) (Table 1$)$. Following supermarkets, midsize stores had the greatest number of separate displays of fruits and vegetables (mean $=9 \pm 6$ ) and general merchandise stores had the greatest number of separate displays of energy-dense snack foods (mean $=29 \pm 12$ ). Regardless of store type, all stores contained more displays of energy-dense snack foods than of fruits and vegetables.

Not one supermarket in the sample had a single display of any type of fruit or vegetable within a meter of their cash registers (Table 2). Although this was true for most stores in the sample, some midsized stores did have displays of fruits or vegetables that were close to cash registers (mean = $1.0 \pm 2.1)$. In contrast to their stocking practices for fruits and vegetables, supermarkets had many displays of energy-dense snack foods within a meter of their cash registers (mean $=$ $19.9 \pm 17.0)$. Out of the ten food groups studied, the top three items displayed within 1 meter of a cash register for supermarkets were candy, salty snack foods, and carbonated beverages (results not shown). For all other store types the top three items close to registers were candy, salty snack foods, or doughnuts and pastries.

\section{Discussion}

This study has demonstrated a method for characterizing the in-store food environment by counting the number of separate displays of foods and determining their proximity to cash registers. Benchmark results on this information for different store types in a major American city are provided for food groups of importance to those working on obesity and urban food access.

Not surprisingly, supermarkets had more displays of fruits and vegetables than other store types, while drug stores or convenience stores had very few. The availability of these "healthful" foods is consistent with general impressions about supermarkets, as well as with a growing literature that has drawn associations between proximity to supermarkets and positive diet or weight status outcomes $[1-4,6,7,39,40]$. No direct comparisons on the number of displays of these foods can be made with previous research, since, to the best of our knowledge, no other studies exist on this topic. 
But our results are consistent with previous in-store studies showing supermarkets with much greater shelf space of fruits and vegetables than other store types [17].

What is more striking about our results is the sizable number of displays of energy-dense snack foods in supermarkets, particularly the large number of displays of these foods within one meter of store cash registers. Industry research has widely supported that $70-83 \%$ of confectionery sales are impulse driven [41]. Recognizing this, most supermarkets and other retail outlets strategically place candy and other items near checkouts. Our findings are consistent with this strategy and with other research on this topic. An observational study of 24 supermarkets in Melbourne, Australia, found that foods displayed at supermarket checkouts were predominantly energy-dense confectionary items [34]. The Food Commission in the United Kingdom surveyed several London supermarkets in 2003 and found all but one of the supermarkets contained confectionery or other snack foods at the checkout [35]. Fruits and vegetables are not usually thought of as impulse items, but supermarkets could certainly experiment with placing snack-size produce-such as individual apples or bananas or prewashed packages of baby carrots - near checkout registers.

While the checkout-counter findings are not surprising, quantitative information about this situation can generate awareness about the problem, and also serve as baseline for measuring progress. To date, most of the policies and programs to address obesity through changes to the food environment have focused on bringing more supermarkets to an area, or on improving the offerings of small stores. For example, financing initiatives have been developed to bring supermarkets to low-income areas [42-47]. In some cases these initiatives can be used by existing small stores in underserved areas, so that they can improve infrastructure to carry more fruits and vegetables. There are also a number of examples of "corner store initiatives," that is, efforts to convince small store owners to carry healthier foods [12, 48, 49].

However, virtually no work is being done on limiting access to energy-dense snack foods in supermarkets. Given the narrow profit margins in the industry and the importance of stocking decisions to store profits, such work would certainly be an unlikely battle. One viable approach might be to focus on improving the quality of check-out stands, and other aspects of supermarkets, through a voluntary recognition program. Just as the LEED (Leadership in Energy and Environmental Design) designation has sought to encourage green building designs [50], so might a similar program seek to promote characteristics of healthy store designs [14]. Whatever the specific goal that public health nutrition advocates might seek, our study and others like it can provide baseline documentation for efforts to improve in-store aspects of the food environment.

This study is not without limitations. While it takes into account the number of separate displays, it does not consider other factors that might influence consumer purchasing, such as the size or location of separate displays or the prices of foods. Another limitation is the exclusion of whole grains, reduced-fat dairy products, and other important food groups from our study. Our goal here was to focus on a few key food groups that have been linked to obesity and that we could appropriately observe in a larger number of stores. This study was conducted at stores only within New Orleans, so the usual caveat about generalizability from a localized study applies here. Finally, although marketing research has indicated the importance of the number and location of displays, we have no evidence on the impacts of such variables on diet and health outcomes. Additional research is certainly needed in this regard.

\section{Conclusions}

As the field of environmental nutrition expands, more comprehensive assessments of neighborhood food environments are needed. This study demonstrates a useful and relatively simple method for characterizing the in-store environment of retail food outlets by counting the number of separate display stands and their proximity to cash registers for fruits, vegetables, and energy-dense snack foods. Although supermarkets are often thought of as contributing to the healthiness of the food environment, they have many more displays of energy-dense snacks than of fruits and vegetables, particularly at check-out counters. Further research is needed to corroborate these findings and to examine the relationship between in-store display variables and diet and health outcomes.

\section{Acknowledgments}

This research was supported by Cooperative Agreement Number 5U48DP001948-02 from the Centers for Disease Control and Prevention, which includes funding for the Prevention Research Center and the Nutrition and Obesity Policy Research and Evaluation Network. The work was also supported by the National Research Initiative, National Institute for Food and Agriculture, US Department of Agriculture (Grant 2006-55215-16711). The findings and conclusions in this paper are those of the authors and do not necessarily represent the official position of the Centers for Disease Control and Prevention or the US Department of Agriculture.

\section{References}

[1] K. Morland, S. Wing, and A. D. Roux, "The contextual effect of the local food environment on residents' diets: the atherosclerosis risk in communities study," American Journal of Public Health, vol. 92, no. 11, pp. 1761-1767, 2002.

[2] B. A. Laraia, A. M. Siega-Riz, J. S. Kaufman, and S. J. Jones, "Proximity of supermarkets is positively associated with diet quality index for pregnancy," Preventive Medicine, vol. 39, no. 5, pp. 869-875, 2004.

[3] D. Rose and R. Richards, "Food store access and household fruit and vegetable use among participants in the US Food Stamp Program," Public Health Nutrition, vol. 7, no. 8, pp. 1081-1088, 2004. 
[4] K. Morland, A. V. Diez Roux, and S. Wing, "Supermarkets, other food stores, and obesity: the atherosclerosis risk in communities study," American Journal of Preventive Medicine, vol. 30, no. 4, pp. 333-339, 2006.

[5] J. N. Bodor, D. Rose, T. A. Farley, C. Swalm, and S. K. Scott, "Neighbourhood fruit and vegetable availability and consumption: the role of small food stores in an urban environment," Public Health Nutrition, vol. 11, no. 4, pp. 413420, 2008.

[6] L. M. Powell, M. C. Auld, F. J. Chaloupka, P. M. O’Malley, and L. D. Johnston, "Associations between access to food stores and adolescent body mass index," American Journal of Preventive Medicine, vol. 33, no. 4, pp. S301-S307, 2007.

[7] L. V. Moore, A. V. D. Roux, J. A. Nettleton, and D. R. Jacobs Jr, "Associations of the local food environment with diet quality-a comparison of assessments based on surveys and geographic information systems: the Multi-Ethnic study of atherosclerosis," American Journal of Epidemiology, vol. 167, no. 8, pp. 917-924, 2008.

[8] M. Franco, A. V. Diez-Roux, J. A. Nettleton et al., "Availability of healthy foods and dietary patterns: the Multi-Ethnic study of atherosclerosis," American Journal of Clinical Nutrition, vol. 89, no. 3, pp. 897-904, 2009.

[9] D. Rose, P. L. Hutchinson, J. N. Bodor et al., "Neighborhood food environments and body mass index. The importance of in-store contents," American Journal of Preventive Medicine, vol. 37, no. 3, pp. 214-219, 2009.

[10] L. M. Powell and Y. Bao, "Food prices, access to food outlets and child weight," Economics and Human Biology, vol. 7, no. 1, pp. 64-72, 2009.

[11] J. N. Bodor, V. M. Ulmer, L. F. Dunaway, T. A. Farley, and D. Rose, "The rationale behind small food store interventions in low-income urban neighborhoods: insights from New Orleans," Journal of Nutrition, vol. 140, no. 6, pp. 1185-1188, 2010.

[12] J. Gittelsohn, H. J. Song, S. Suratkar et al., "An urban food store intervention positively affects food-related psychosocial variables and food behaviors," Health Education and Behavior, vol. 37, no. 3, pp. 390-402, 2010.

[13] W. R. Dean and J. R. Sharkey, "Rural and urban differences in the associations between characteristics of the community food environment and fruit and vegetable intake," Journal of Nutrition Education and Behavior, vol. 43, no. 6, pp. 426-433, 2011.

[14] Committee on Childhood Obesity Prevention Actions for Local Governments and Institute of Medicine, Local Government Actions to Prevent Childhood Obesity, The National Academies Press, Washington, DC, USA, 2009.

[15] Office of Management and Budget. Budget of the United States Government, Fiscal Year 2012, http://www.whitehouse.gov/ sites/default/files/omb/budget/fy2012/assets/budget.pdf, 2011.

[16] S. N. Zenk, A. J. Schulz, B. A. Israel, S. A. James, S. Bao, and M. L. Wilson, "Neighborhood racial composition, neighborhood poverty, and the spatial accessibility of supermarkets in metropolitan Detroit," American Journal of Public Health, vol. 95, no. 4, pp. 660-667, 2005.

[17] T. A. Farley, J. Rice, J. N. Bodor, D. A. Cohen, R. N. Bluthenthal, and D. Rose, "Measuring the food environment: shelf space of fruits, vegetables, and snack foods in stores," Journal of Urban Health, vol. 86, no. 5, pp. 672-682, 2009.

[18] C. L. Connell, M. K. Yadrick, P. Simpson, J. Gossett, B. B. McGee, and M. L. Bogle, "Food supply adequacy in the lower
Mississippi delta," Journal of Nutrition Education and Behavior, vol. 39, no. 2, pp. 77-83, 2007.

[19] P. M. Morris, L. Neuhauser, and C. Campbell, "Food security in rural America: a study of the availability and costs of food," Journal of Nutrition Education, vol. 24, supplement 1, pp. 52S58S, 1992.

[20] K. M. Jetter and D. L. Cassady, "The availability and cost of healthier food alternatives," American Journal of Preventive Medicine, vol. 30, no. 1, pp. 38-44, 2006.

[21] K. Glanz, J. F. Sallis, B. E. Saelens, and L. D. Frank, "Nutrition environment measures survey in stores (NEMS-S). Development and evaluation," American Journal of Preventive Medicine, vol. 32, no. 4, pp. 282-289, 2007.

[22] J. R. Sharkey, S. Horel, and W. R. Dean, "Neighborhood deprivation, vehicle ownership, and potential spatial access to a variety of fruits and vegetables in a large rural area in Texas," International Journal of Health Geographics, vol. 9, p. 26, 2010.

[23] B. Bustillos, J. R. Sharkey, J. Anding, and A. McIntosh, "Availability of more healthful food alternatives in traditional, convenience, and nontraditional types of food stores in two rural texas counties," Journal of the American Dietetic Association, vol. 109, no. 5, pp. 883-889, 2009.

[24] S. Cummins and S. Macintyre, "A systematic study of an urban foodscape: the price and availability of food in greater Glasgow," Urban Studies, vol. 39, no. 11, pp. 2115-2130, 2002.

[25] S. N. Zenk, A. J. Schulz, B. A. Israel, S. A. James, S. Bao, and M. L. Wilson, "Fruit and vegetable access differs by community racial composition and socioeconomic position in Detroit, Michigan," Ethnicity and Disease, vol. 16, no. 1, pp. 275-280, 2006.

[26] A. D. Liese, K. E. Weis, D. Pluto, E. Smith, and A. Lawson, "Food store types, availability, and cost of foods in a rural environment," Journal of the American Dietetic Association, vol. 107, no. 11, pp. 1916-1923, 2007.

[27] J. F. Sallis, P. R. Nader, J. W. Rupp, C. J. Atkins, and W. C. Wilson, "San Diego surveyed for heart-healthy foods and exercise facilities," Public Health Reports, vol. 101, no. 2, pp. 216-219, 1986.

[28] M. Franco, A. V. Diez Roux, T. A. Glass, B. Caballero, and F. L. Brancati, "Neighborhood characteristics and availability of healthy foods in Baltimore," American Journal of Preventive Medicine, vol. 35, no. 6, pp. 561-567, 2008.

[29] R. C. Curhan, "The effects of merchandising and temporary promotional activities on the sales of fresh fruits and vegetables in supermarkets," Journal of Marketing Research, vol. 11, no. 3, pp. 286-294, 1974.

[30] J. J. Inman and R. S. Winer, "Where the rubber meets the road: a model of in-store consumer decision-making," Tech. Rep. 98-122, Marketing Science Institute, Cambridge, Mass, USA, 1998.

[31] J. J. Inman, R. S. Winer, and R. Ferraro, "The interplay among category characteristics, customer characteristics, and customer activities on in-store decision making," Journal of Marketing, vol. 73, no. 5, pp. 19-29, 2009.

[32] J. B. Wilkinson, J. B. Mason, and C. H. Paksoy, "Assessing the impact of short-term supermarket strategy variables," Journal of Marketing Research, vol. 16, pp. 72-86, 1982.

[33] P. Chandon, J. W. Hutchinson, E. T. Bradlow, and S. H. Young, "Does in-store marketing work? Effects of the number and position of shelf facings on brand attention and evaluation at the point of purchase," Journal of Marketing, vol. 73, no. 6, pp. $1-17,2009$. 
[34] H. Dixon, M. Scully, and K. Parkinson, "Pester power: snackfoods displayed at supermarket checkouts in Melbourne, Australia," Health Promotion Journal of Australia, vol. 17, no. 2, pp. 124-127, 2006.

[35] The Food Commission, Supermarkets Told to Chuck Snacks off the Checkout!, vol. 63, The Food Commission, London, UK, 2003.

[36] B. J. Rolls, A. Drewnowski, and J. H. Ledikwe, "Changing the energy density of the diet as a strategy for weight management," Journal of the American Dietetic Association, vol. 105, no. 5, pp. S98-S103, 2005.

[37] M. B. Schulze, J. E. Manson, D. S. Ludwig et al., "Sugarsweetened beverages, weight gain, and incidence of type 2 diabetes in young and middle-aged women," Journal of the American Medical Association, vol. 292, no. 8, pp. 927-934, 2004.

[38] D. Rose, J. N. Bodor, C. M. Swalm, J. C. Rice, T. A. Farley, and P. L. Hutchinson, "Deserts in New Orleans? Illustrations of urban food access and implications for policy," in Proceedings of the Electronic conference from Understanding the Economic Concepts and Characteristics of Food Access, UM-National Poverty Center and USDA-Economics Research Service, Washington, DC, USA, January 2009.

[39] R. P. Lopez, "Neighborhood risk factors for obesity," Obesity, vol. 15, no. 8, pp. 2111-2119, 2007.

[40] J. N. Bodor, J. C. Rice, T. A. Farley, C. M. Swalm, and D. Rose, "The association between obesity and urban food environments," Journal of Urban Health, vol. 87, no. 5, pp. 771-781, 2010.

[41] Solid Growth in Bars, 2001, Convenience \& Impulse Retailing, http://www.c-store.com.au/magazine/article.php?id=249 .

[42] Pennsylvania Fresh Food Financing Initiative. The Food Trust, http://www.trfund.com/resource/downloads/Fresh_Food_Financing_Initiative_Comprehensive.pdf, 2011.

[43] T. Giang, A. Karpyn, H. B. Laurison, A. Hillier, and R. D. Perry, "Closing the grocery gap in underserved communities: the creation of the Pennsylvania fresh food financing initiative," Journal of Public Health Management and Practice, vol. 14, no. 3, pp. 272-279, 2008.

[44] Report by the New Orleans Food Policy Advisory Committee, "Building healthy communities: expanding access to fresh food retail," Tech. Rep., The Prevention Research Center at Tulane University and The Food Trust, New Orleans, La, USA, 2008.

[45] Report of the Healthy Food Retail Study Group, "Recommendations for a Louisiana healthy food retail financing program," Tech. Rep., The Prevention Research Center at Tulane University and The Food Trust, New Orleans, La, USA, 2009.

[46] New Orleans Fresh Food Retailer Initiative. City of New Orleans, Hope Enterprise Corporation and The Food Trust, http://www.hope-ec.org/images/documents/neworleansfresh foodretailerinitiative-programoverview-4-14-11.pdf, 2011.

[47] Healthy Food Financing Initiative Implementation Plan. United States Department of Agriculture, http://www.ams .usda.gov/AMSv1.0/getfile?dDocName=STELPRDC5085689, 2011.

[48] J. Gittelsohn, V. Vijayadeva, N. Davison et al., "A food store intervention trial improves caregiver psychosocial factors and childrens dietary intake in Hawaii," Obesity, vol. 18, supplement 1, pp. S84-S90, 2010.

[49] Institute of Medicine and NRC, The Public Health Effects of Food Deserts: Workshop Summary, The National Academies Press, Washington, DC, USA, 2009.
[50] U.S. Green Building Council, What Leed Is, http://www.usgbc .org/DisplayPage.aspx?CMSPageID=1988. 


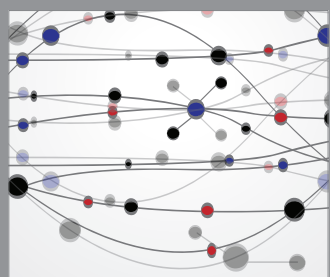

The Scientific World Journal
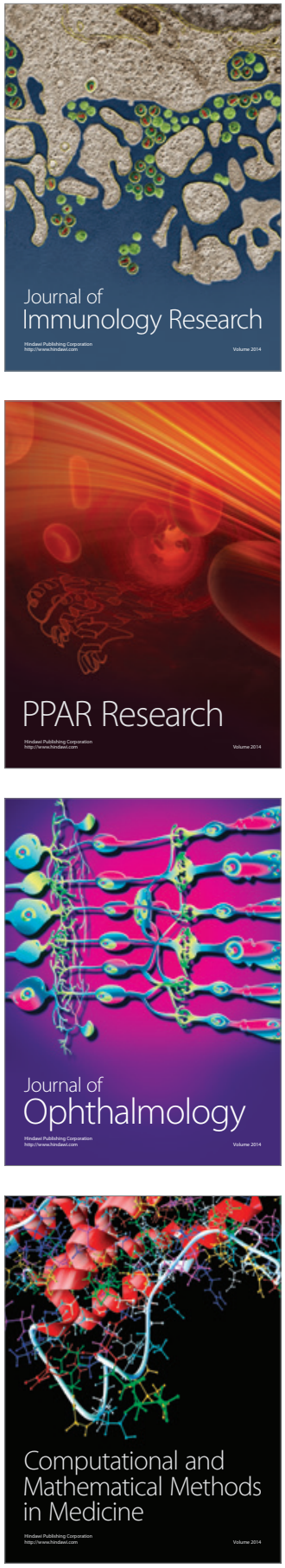

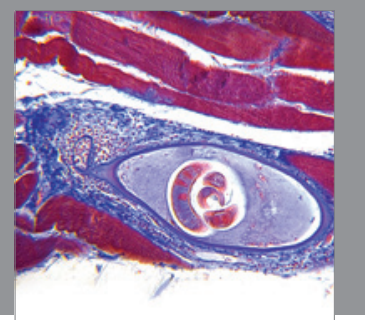

Gastroenterology

Research and Practice
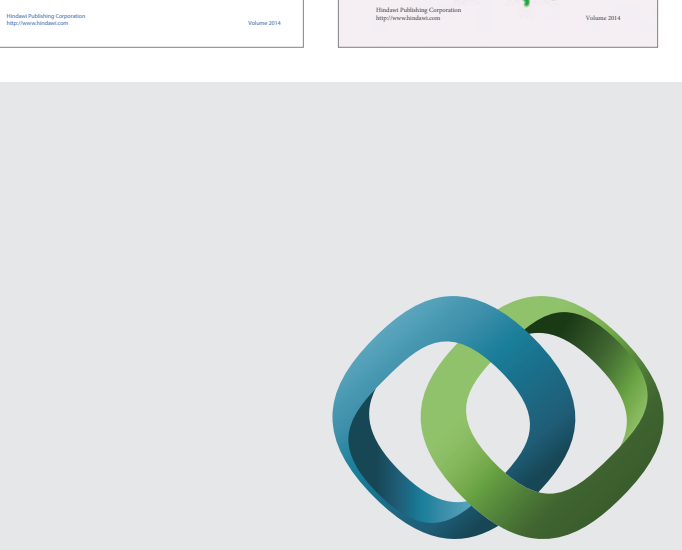

\section{Hindawi}

Submit your manuscripts at

http://www.hindawi.com
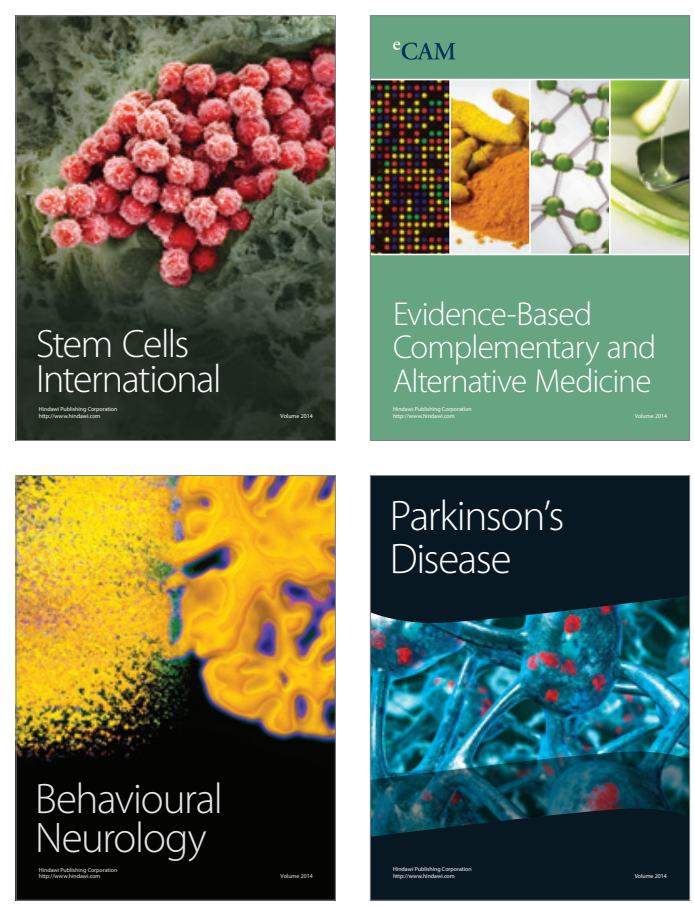

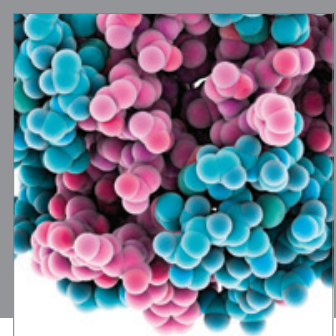

Journal of
Diabetes Research

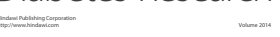

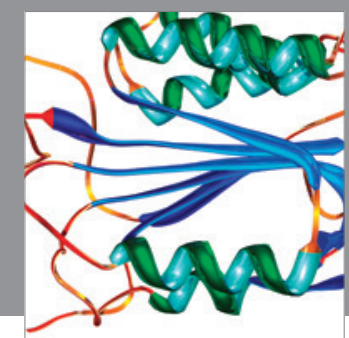

Disease Markers
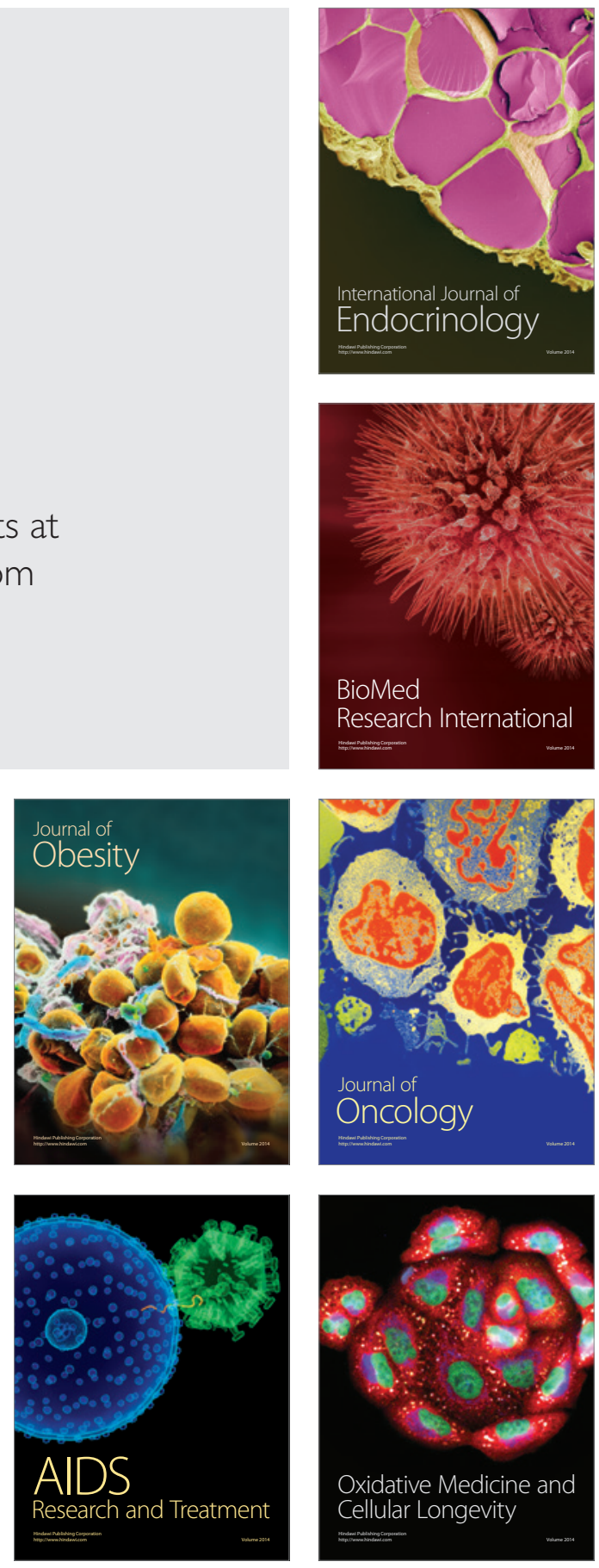